TECHNICAL TRANSACTIONS 12/2017

CZASOPISMO TECHNICZNE 12/2017

PHYSICS

DOI: $10.4467 / 2353737 X C T .17 .223 .7766$

Marcin Majka (marcin.majka@if.edu.pl)

The Henryk Niewodniczański Institute of Nuclear Physics Polish Academy of Sciences

Giacomo Gadda

Angelo Taibi

Department of Physics and Earth Sciences, University of Ferrara

\title{
Piotr Zieliński
}

Institute of Physics, Cracow University of Technology

\section{EFFECTS OF AORTIC VALVE DISEASES ON PRESSURE PROFILES \\ IN SELECTED LOCATIONS OF THE HUMAN ARTERIAL SYSTEM}

\author{
WŁYW CHORÓB ZASTAWKI AORTALNEJ NA PRZEBIEGI CIŚNIENIA \\ W WYBRANYCH MIEJSCACH UKŁADU TĘTNICZEGO CZŁOWIEKA
}

\begin{abstract}
Aortic valve diseases such as aortic stenosis and aortic regurgitation, are the most frequent valvular heart diseases. The lesions in the valves affect circulation in the whole arterial system. We study the effects with the use of a 1-D model in which an arterial segment transmits a single mode of pulse waves. The appropriate reflection coefficient and the form of the stroke pressure are devised to simulate the function of the healthy and morbid aortic valve. The time dependence of the arterial pressure is predicted at the most important locations of the arterial tree. A remarkable result is that little variations of the reflection coefficient of the vale due to the modelled diseases cause significant changes of the pressure profiles, especially at the ascending aorta, the left brachial artery and in the anterior communicating artery.
\end{abstract}

Keywords: arterial model, aortic valve diseases, aortic stenosis, aortic regurgitation, transmission line, pressure profiles, Circle of Willis

\section{Streszczenie}

Zwężenie zastawki aortalnej (stenosis ostii arteriosi sinistri) oraz niedomykalnośćzastawki aortalnej (insufficientia valvulaeaortae) sąnajczęstszymichorobamizastawekserca.Zmianychorobowezastawkiniewątpliwiewplywają na obieg krwi w całym układzie tętniczym. Wpływ tych zmian zbadano przy użyciu jednowymiarowego modelu, w którym każdy segment tętnicy transmituje tylko jeden mod fali tętna. Opracowane odpowiednie wartości współczynnika odbicia zastawki aortalnej oraz ksztalt ciśnienia generowanego przy skurczu serca symulują realistycznie działanie zastawki zdrowej i chorej. Otrzymane wyniki pozwalają przewidywać przebiegi ciśnienia w najistotniejszych miejscach drzewa tętniczego. Zadziwiający jest fakt, że nawet najmniejsze różnice w współczynniku odbicia od zastawki powodują znaczące zmiany w profilach ciśnienia, a w szczególności w aorcie wstępującej, lewej tętnicy ramiennej oraz w tętnicy lączącej przedniej.

Słowa kluczowe: model tętniczy, chory zastawki aortalnej, zwężenie zastawki aortalnej, niedomykalność zastawki aortalnej, linia transmisyjna, przebiegi ciśnienia, koło Willisa 


\section{Introduction}

Aortic stenosis (AS) and aortic regurgitation (AR) are the most common valvular heart diseases in developed countries [1-6]. AS is often a gradually progressive degenerative disease which results in the calcification of the aortic valve leaflets [3]. This causes an obstruction to the blood flow from the left ventricle to the aorta which leads to an increase in the left ventricular afterload. In contrast to that $A R$ allows for a diastolic flow of blood from the aorta into the left ventricle. The incidence of clinically significant AR increases with age, typically peaking in the fourth to sixth decade of life [6]. AR may be caused by malfunction of the valve leaflets themselves, by dilatation of the aortic root and annulus.

Hypertension can modify the physical examination findings of AS, particularly in the elderly patient [7]. The characteristic exploratory findings of AS are all influenced by peripheral aortic impedance, wave reflections, post stenotic aortic dilatation, and vessel stiffness. If AS coexists with hypertension, the valvular obstruction and the increased vascular resistance complementarity raises the systolic stress of the doubly loaded left ventricle [8]. Moreover,

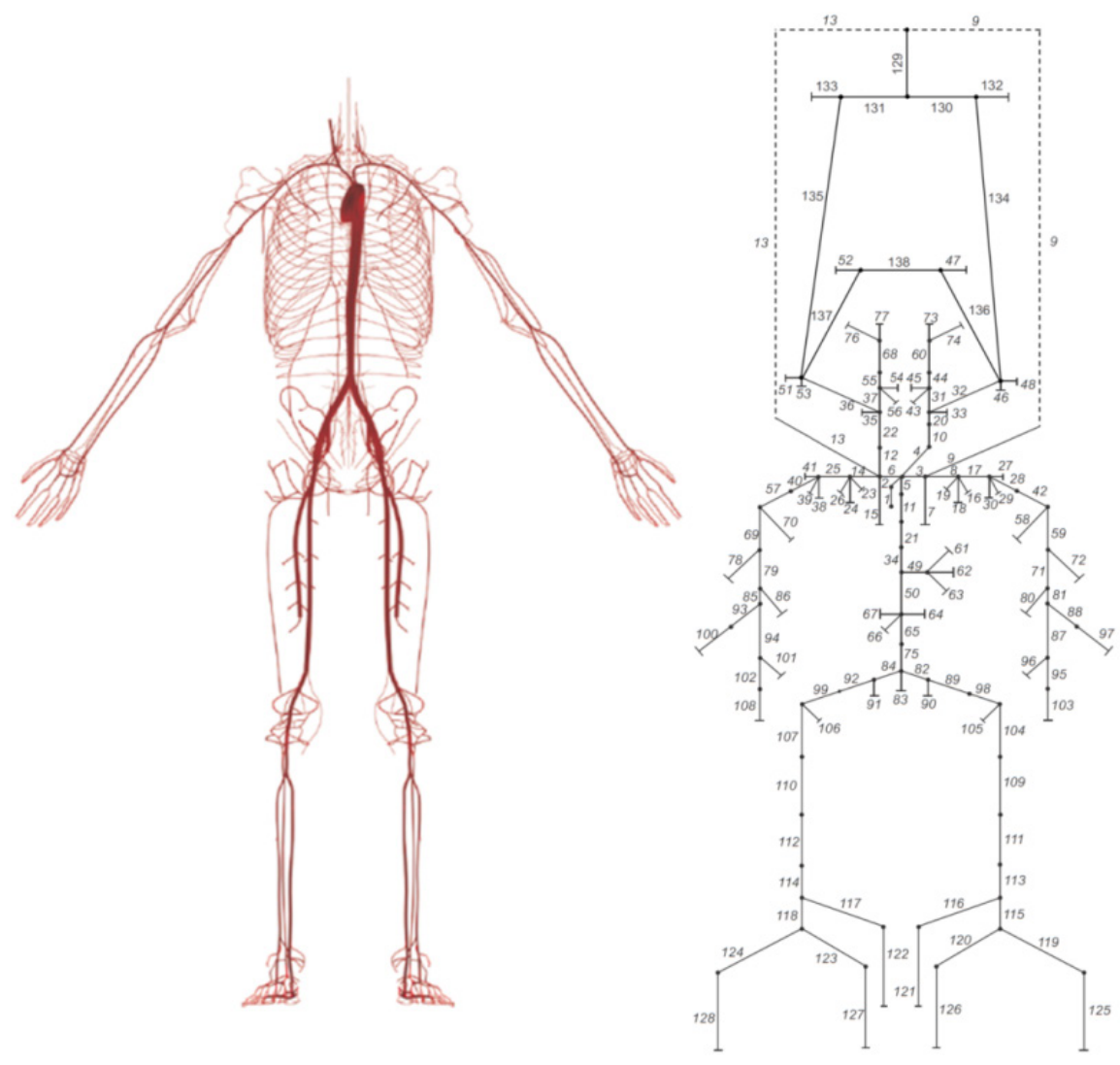

Fig. 1. The arterial tree of the human body. Form right - the topology of model with 138 segments available in [10], From left - real topology 
these two sources of afterload interact following a characteristic behaviour. The intrinsic systolic load is competitively modified by the extrinsic load (the systemic blood pressure) in an opposite and parallel fashion $[3,8]$. This mechanism explains why vascular biomechanics may also modify the quantification of AS severity. However, the magnitude, clinical relevance, and diagnostic consequences of this vascular-valvar interaction are incompletely understood.

AR causes volume overload of the left ventricle [6]. The total stroke volume ejected by the left ventricle (sum of effective stroke volume plus regurgitant volume) is increased; in severe AR the regurgitant volume may equal or even exceed the effective stroke volume $[4,5]$. An increase in the left ventricle end-diastolic volume is the main compensatory mechanism needed to maintain a normal effective stroke volume. The left ventricular ejection fraction is initially normal, however, the left ventricle end-diastolic pressure rises [6]. In time the left ventricle end-diastolic volume continues to increase further and the ejection fraction drops. In AR there is not only a volume overload but also an increase in the afterload and therefore of systolic wall stress. This distinguishes AR from mitral regurgitation [9], where a left ventricle volume overload is also present, but where the systolic wall stress is normal or even lower, since the regurgitant blood is ejected into the low pressure left atrium.

In the present paper we use a 1-D model of the arterial tree to study the effects of AS and $\mathrm{AR}$ on the pressure time dependence in peripheral vessels. The model consists of 138 arterial segments transmitting pulse waves.

The topology of the models is presented in Fig. 1.

The purpose of the present study is to give a quantitative account of the effect of AS and $\mathrm{AR}$ on the temporal pressure in the arterial system, i.e. to find out how the corresponding disturbances of pressure have an effect on pressure profiles in the ascending aorta, in the left ulnar artery and in the anterior communicating artery. The problem is interesting from the fundamental research point of view, namely to what extent passive models, i.e. those without voltage and/or current sources are capable of reproducing the physiology of the arterial system (for models of neural heart rate control via baroreceptors and reflex arc see e.g. [1113]). The adequacy of the present computations can be partly verified with the measurement results from patients with AS and AR available in the literature [1-9].

\section{Materials and methods}

\subsection{Propagation of pulse waves}

The elasticity of vessel walls is at the origin of the wave-like character of blood flow in arteries. In principle the number of propagation modes is infinite $[15,16]$, but the most significant effect belongs to the Young mode easily palpable at the wrist. Restricting the attention to this mode allows one to treat the vessels as monomode 1-D waveguides.

The method of obtaining a 1-D equation of motion in a distensible vessel of varying cross section has been developed in $[14,17,18]$. The governing equations involve conservation of mass and the momentum balance in a control volume of the $1-\mathrm{D}$ vessel $[17,18]$. The 
volumetric flow, as a function of space $x$ and time $t, Q(x, t)=A U$ relates the cross section area $A$ and the average axial velocity $U$ tethered in longitudinal direction. The pressure $P$ is assumed constant across the section, whereas the radial and azimuthal components of velocity are neglected. Gravitational effects are ignored because all the simulations performed in this work refer to a supine subject. The system of equations is:

where

$$
\left\{\begin{array}{l}
\frac{\partial A}{\partial t}+\frac{\partial Q}{\partial x}=0 \\
\frac{\partial Q}{\partial t}+\frac{\partial}{\partial x}\left(\alpha \frac{Q^{2}}{A}\right)+\frac{A}{\rho} \frac{\partial P}{\partial x}=\frac{f}{\rho}
\end{array}\right.
$$

$\rho$ - the blood density,

$f(x, t) \quad-$ the frictional force per unit length,

$\alpha(x, t)=\frac{1}{A U^{2}} \int_{A} u^{2} d \sigma-$ the non-dimensional profile shape factor (also called the Coriolis the velocity profile $\mathbf{u}=(\mathbf{x}, t)[19]$.

The blood density $\rho$ and viscosity $\mu$ are assumed to be constant at $37^{\circ} \mathrm{C}$, so that $\rho=1050 \mathrm{~kg}$ $\mathrm{m}^{-3}$ and $\mu=4.0 \mathrm{mPa}$ s [14]. Eq. (1) can be derived by integrating the incompressible NavierStokes equations over a generic cross section of a cylindrical domain [19-24].

In 1-D modelling the velocity profile is commonly assumed to be constant in shape and axisymmetric. A typical profile satisfying the no-slip condition $\left(\left.u\right|_{r=R}=0\right)$ is $[19,20]$ :

$$
u(x, r, t)=U \frac{\xi+2}{\xi}\left[1-\left(\frac{r}{R}\right)^{\xi}\right]
$$

where

$r \quad-$ the radial coordinate,

$R(x, t) \quad$ - the radius of the lumen (assumed to be circular),

$\xi=\frac{2-\alpha}{\alpha-1}-$ a constant.

The velocity profile is required to close the system of equations (1), since it directly affects convective accelerations and the frictional term $f(x, t)$. For $\xi=2$ the Coriolis coefficient is equal to $4 / 3$ and it leads to the Poiseuille parabolic velocity profile and the corresponding frictional force equal to $f=-8 \mu \pi U$. This limit is valid for the narrowest resistive vessels. On the other hand, when considering the largest vessels one should consider flattened velocity profile as has been shown by Womersley [25]. For this reason we use the value $\xi=9$ and, appropriately, $\alpha=1.1$.

An explicit algebraic relationship between $P$ and $A$ (the tube law) is also required to close Eq. (1). The tube law is determined by the viscoelastic properties of the vessel walls [26]. Voigt-type visco-elastic laws reproduce, in the first approximation, the main effects of the 
walls' properties on the blood flow in large arteries, including hysteresis and creep [27-32]. An example of this type of law that neglects the effects of wall inertia and longitudinal prestress [36] is given by [32]:

$$
\begin{gathered}
P=P_{e}(A ; x)+\frac{\Gamma(x)}{A_{0}(x) \sqrt{A}} \frac{\partial A}{\partial t} \\
P_{e}(A ; x)=P_{e x t}+\frac{\beta(x)}{A_{0}(x)}\left(\sqrt{A}-\sqrt{A_{0}(x)}\right), \\
\beta(x)=\frac{4}{3} \sqrt{\pi} E(x) h(x), \quad \Gamma(x)=\frac{2}{3} \sqrt{\pi} \phi h(x),
\end{gathered}
$$

where

$P_{e} \quad-$ the elastic component of pressure,

$h(x) \quad$ - the wall thickness,

$\beta(x) \quad$ - a value related to the wall elasticity, independent of the transmural pressure,

$\Gamma(x) \quad$ a value related to the wall viscosity, independent of the transmural pressure,

$E(x)$ - the Young's modulus of the vessel wall,

$\varphi(x) \quad-$ the dynamic viscosity of the vessel wall.

The reference area $A_{0}(x)$ is the vessel area when $P=P_{\text {ext }}$ and $\partial A / \partial t=0$, which are typical initial conditions for numerical analysis. Therefore, the local cross-sectional area $A(x, t)$ will depend on the shape of the artery given by $A_{0}(x)$ and the mechanical properties of the wall, which may change with $x$. For example, the arterial wall becomes stiffer as the distance from the heart increases.

In the 1-D formulation the nodes connecting the arterial segments are treated as discontinuities, which is consistent with the long-wavelength approximation. Detailed 3-D calculation of flow at arterial bifurcations show that the flow is generally very complex with the possibility of transient separation and the development of secondary flows [14]. Most of these flow features are confined to the region near the bifurcation and the long wave approximation allows one to neglect their effects on the pulse wave in the 1-D formulation.

The linearization of the governing equations yields an analogy with a transmission line: where resistance $R$, inductance $L$, and capacitance $C$ are calculated per unit length of vessel as follows:

$$
R=\frac{2(\xi+2) \pi \mu}{A_{0}^{2}}, L=\frac{\rho}{A_{0}}, C=\frac{2 A_{0}^{\frac{3}{2}}}{\beta} .
$$

Eq. (5) allows us to determine the wave speed $c=\sqrt{1 / C L}$ and the characteristic impedance $Z=\rho c / A_{0}$ for every segment of a given artery $[14]$. These quantities determine the transmission and reflection coefficients at every bifurcation of the arterial tree. 


\subsection{Models of the arterial tree}

We solve the nonlinear 1-D equations (1) and (3) using finite element methods, such as Galerkin [33] and Taylor-Galerkin (combined with operator splitting techniques) [14] schemes. The linearized system of governing equations yields an analytical solution for wave reflection and transmission where the physical properties of the arteries change. At a splitting and merging junction, the reflection coefficients $R_{f}^{a}, R_{f}^{b}, R_{f}^{c}$ for wave propagating in the parent $a$ and two daughter, vessels $b$ and $c$ respectively can be defined as the ratio of the pressure amplitude in the reflected wave to the pressure amplitude in the incident wave. They can be expressed as a function of the characteristic impedance of each segment:

$$
R_{f}^{a}=\frac{\left(Z_{0}^{a}\right)^{-1}-\left(Z_{0}^{b}\right)^{-1}-\left(Z_{0}^{c}\right)^{-1}}{\left(Z_{0}^{a}\right)^{-1}+\left(Z_{0}^{b}\right)^{-1}+\left(Z_{0}^{c}\right)^{-1}} .
$$

The transmission coefficients $T_{a}, T_{b}, T_{c}$ for waves propagating in the parent, $a$, and two daughter, $b$ and $c$, vessels can be defined as the ratio of the pressure perturbation transmitted to the other two vessels to the pressure perturbation in the vessel where the initial wave is propagated:

$$
T^{j}=1+R_{f}^{j}, j=a, b, c .
$$

In any system, the reflection and transmission coefficients are related with a mismatch of characteristic impedance. When applied to the triple junctions the Kirchhoffs laws for a 1D conductor provide Eqs. (6) and (7).

The outlet of each terminal branch is assumed to be coupled to a single resistance $R_{1}$ [34], so that the corresponding reflection coefficient is:

$$
R_{f}=\frac{R_{1}-Z_{0}}{R_{1}+Z_{0}} .
$$

The coefficient relates the pressure change associated with the reflected wave to that of the incident wave.

Putting $R_{1}=0$ yields spurious wave reflections and $R_{1}=Z_{0}$ corresponds to complete absorption of any incoming wave [34], where $Z_{0}$ is the characteristic impedance of the peripheral segment. We use the latter assumption in all the terminal branches of the model. At the aortic valve we define a time-dependent reflection coefficient, $R_{v}$. We have $R_{v}>1$ (more pressure is reflected than it comes in) when the aortic valve is open and $R_{v}=1$ (total reflection) when it is closed [35].

\subsection{Model of aortic stenosis}

We consider an AS as a change of the aortic valve reflection coefficient $\left(R_{v}\right)$. The AS occurs, in our model, abruptly during normal work of the heart. In each simulation series the 
occlusion starts after 10 cycles of the heart. We selected 3 different segments of the arterial tree, to present the reaction of the pressure waveforms to the AS. This model allows us to see how the pressure values evolve with time at any desired location of the arterial tree. We present the results in ascending aorta, in left brachial artery and in the anterior communicating artery.

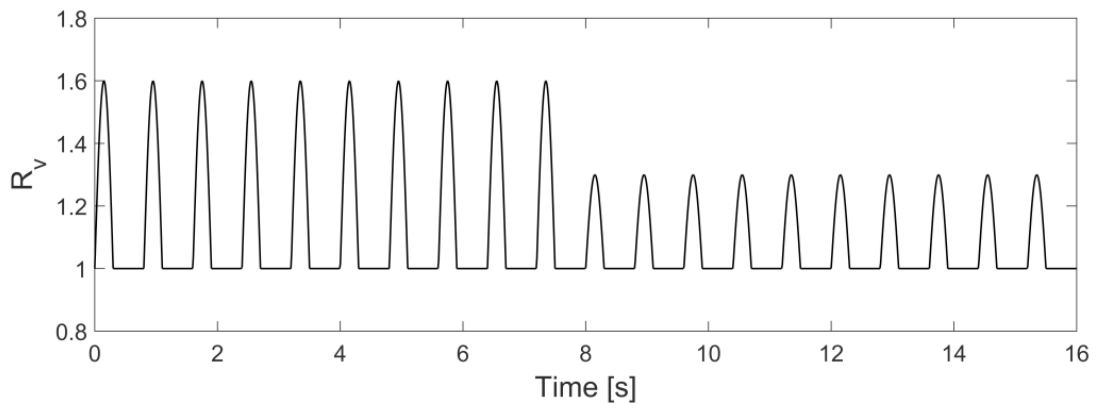

Fig. 2. Valve reflection coefficient during the AS as a function of time

In the normal work the reflection coefficient $R_{v}$ of the aortic valve, i.e. at the heart point of the arterial tree, is equal to 1.6 during the systole, and 1 during the diastole [35]. A stenosis provokes two simultaneous effects: i) a decrease in the stroke volume and ii) the corresponding decrease in the effective reflection coefficient at the root of our model, i.e. heart. Our computations assume a proportional decrease in both quantities. Accordingly the reflection coefficient corresponding to systole now amounts to $R_{v}=1.3$. The reflection coefficient remains equal to 1 in the stage of diastole. Fig. 2 shows the modelled reflection coefficient $R_{v}$ at the heart point as a function of time; the first 10 cardiac cycles represent a healthy heart, and the stenosis (AS) occurs suddenly at the $11^{\text {th }}$ stroke.

\subsection{Model of aortic regurgitation}

We consider an AR as a change of the aortic valve reflection coefficient $\left(R_{v}\right)$. The AR occurs, in our model, during normal work of the heart. In each simulation series the occlusion starts after 10 cycles of the heart.

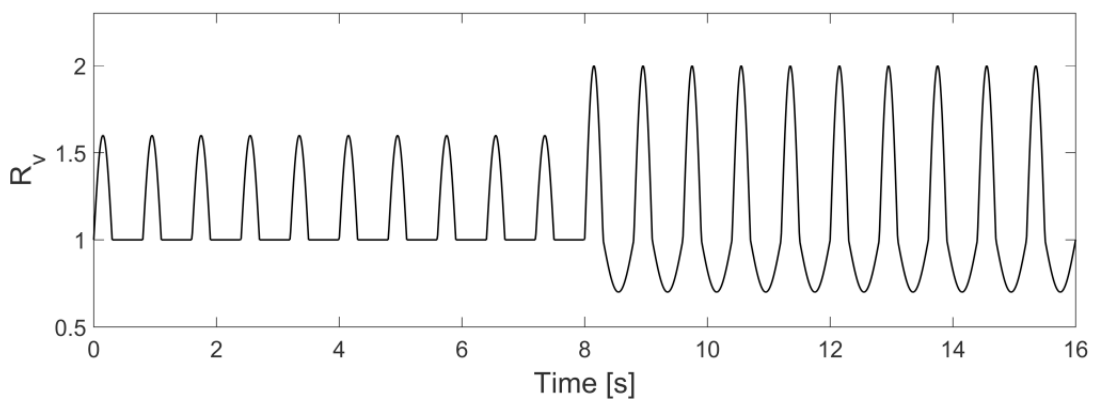

Fig. 3. Valve reflection coefficient during the $A R$ as a function of time 
In the normal work during the systole in the crucial point $R_{v}$ is equal to 1.6 , and during the diastole $R_{v}$ is equal to 1 [35]. As far as the $\mathrm{AR}$ is concerned, one knows that the stroke volume increases in the systole, but the valve remains partly opened in the diastole. Accordingly, in our computation, the reflection coefficient during systole is increased to $R_{v}=2$, but it drops below 1, i.e. $R_{v}=0.7$ in diastole. The changes in the reflection coefficient are proportional to the changes in the stroke volume. Fig. 3 shows the $R_{v}$ as a function of time. After 10 cardiac cycles the AR occurs.

\section{Results}

\subsection{Aortic stenosis}

Fig. 4a shows the pressure waveform in the segment 1 (Ascending aorta in model of 138 arteries, see Fig. 1), in response to the standard heart action given in inset of Fig. 4a.

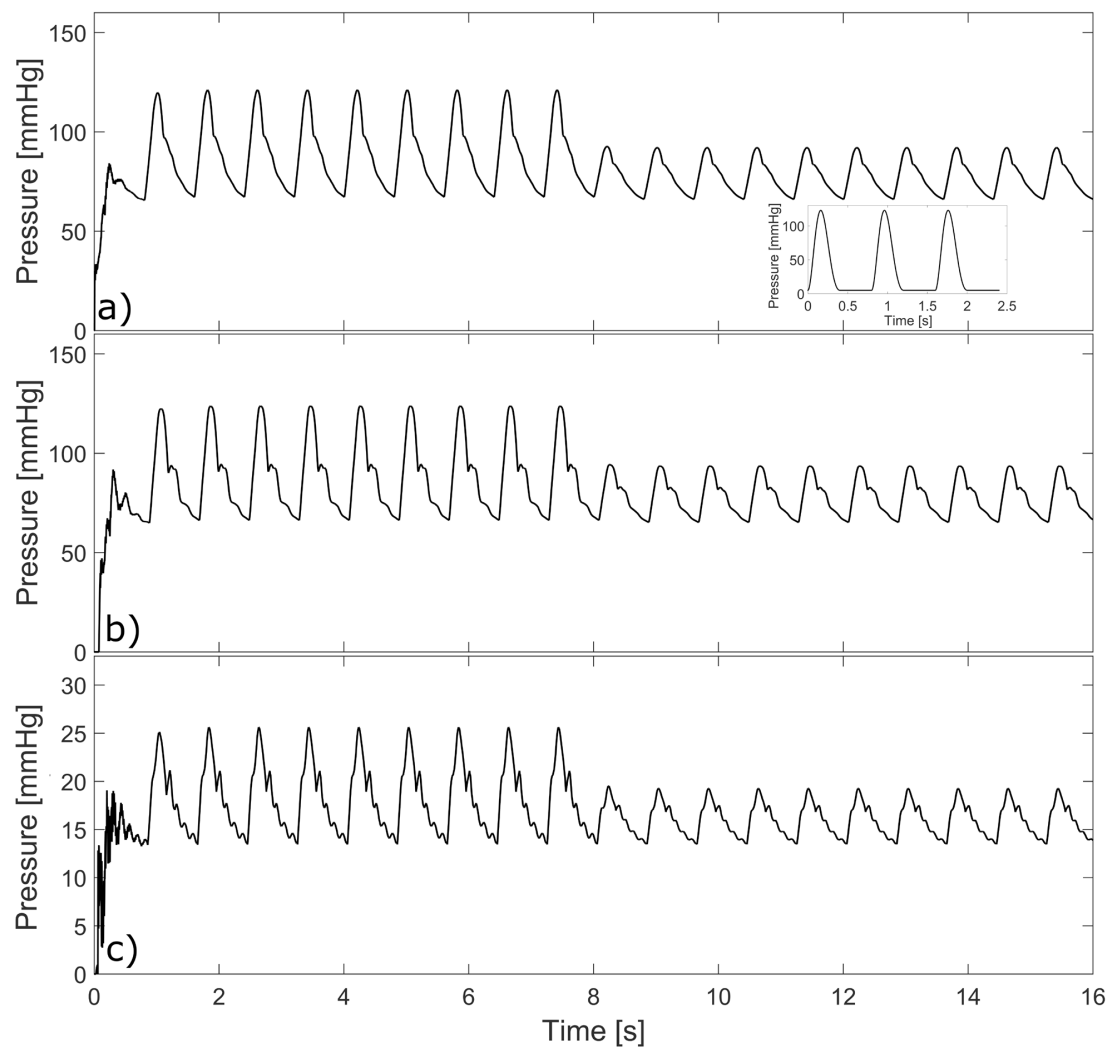

Fig. 4. The pressure waveform in a) ascending aorta, b) left brachial artery and in c) anterior communicating artery during 20 cycles of the heart at AS. The inset in Fig. 4a represents the ventricular pressure waveform in normal condition. The onset of AS takes place after 10 first cycles of heart 
The pressure profile stabilizes after about 2 cardiac cycles. Fig. $4 \mathrm{~b}$ shows the pressure waveform in the segment 59 (Left brachial artery in model of 138 arteries, see Fig. 1). Fig. 4c shows the pressure waveform in the segment 138 (Anterior communicating artery in model of 138 arteries, see Fig. 1). After 10 cardiac cycles the AS occurs.

As we can see from Fig. $4 \mathrm{a}$ and Fig. $4 \mathrm{~b}$, the AS causes a huge decrease in the pressure in ascending aorta and in left brachial artery, where the systolic pressure decreases by more than $30 \mathrm{mmHg}$. The diastolic pressure has not changed. In Fig. $4 \mathrm{c}$ we can see a pressure waveform in the anterior communicating artery, where AS causes also a decrease in the systolic pressure. The drop is surprisingly low, however, i.e. by $5 \mathrm{mmHg}$ only. If the pressure dropped to 0 $\mathrm{mmHg}$, the blood flow in the anterior communicating artery would be also equal to 0 . This would amount to a cerebral hypoxia. However, because of the geometry of the arterial tree, and the rheological properties of the vessels, the pressure inside the anterior communicating artery remains still nonzero during systole. This is an example of the protective properties of the arterial tree for brain [36]. The diastolic pressure in this case has not changed similarly ascending aorta and in left brachial artery. The obtained waveforms are in agreement with experimental data $[1-3,7]$.

\subsection{Aortic regurgitation}

Fig. 5a shows the pressure waveform in the segment 1 (Ascending aorta in model of 138 arteries, see Fig. 1), in response to the standard heart action given in inset of Fig. 4a. The pressure profile stabilizes after about 2 cardiac cycles. Fig. $5 \mathrm{~b}$ shows the pressure waveform in the segment 59 (Left brachial artery in model of 138 arteries, see Fig. 1). Fig. 5c shows the pressure waveform in the segment 138 (Anterior communicating artery in model of 138 arteries, see Fig. 1). After 10 cardiac cycles the AR occurs.

As we can see from Fig. 5a and Fig. 5b, the AR causes a huge increase in the systolic pressure and also a decrease in the diastolic pressure in the ascending aorta and the left brachial artery, where the systolic pressure increases by more than $40 \mathrm{mmHg}$ and the diastolic pressure decreases by $25 \mathrm{mmHg}$. In Fig. $5 \mathrm{c}$ we can see a pressure waveform in the anterior communicating artery, where AR causes also an increase in systolic pressure but only by 8 $\mathrm{mmHg}$ and decrease in diastolic pressure only by $4 \mathrm{mmHg}$. The waveforms obtained are in agreement with experimental data $[4,6,9]$.

The results show the theoretical behaviour of the pressure waveforms at the major vessels of the human arterial system in cases of AS and AR. As has been shown, all the data obtained from the model are in qualitative agreement with experimental data reported in $[1-4,6,7$, 9]. The typical values of the pressure (systole/diastole) in the ascending aorta for AS are $\sim 110 / 75 \mathrm{mmHg}[1-3]$, and for AR are $\sim 150 / 60 \mathrm{mmHg}$ [4-6]. A comparison of these clinical results to results from our models shows a really good agreement. However, our model of the arterial tree reproduces only a mechanical response of the arterial tree. The compensatory mechanisms, e.g. baroreflex or/and humoral responses are still to be studied. Therefore, our results should be treated as a plausible prediction of the behaviour of the arterial system in the very first stages after the events and, on the other hand, as a passive-mechanical reference 


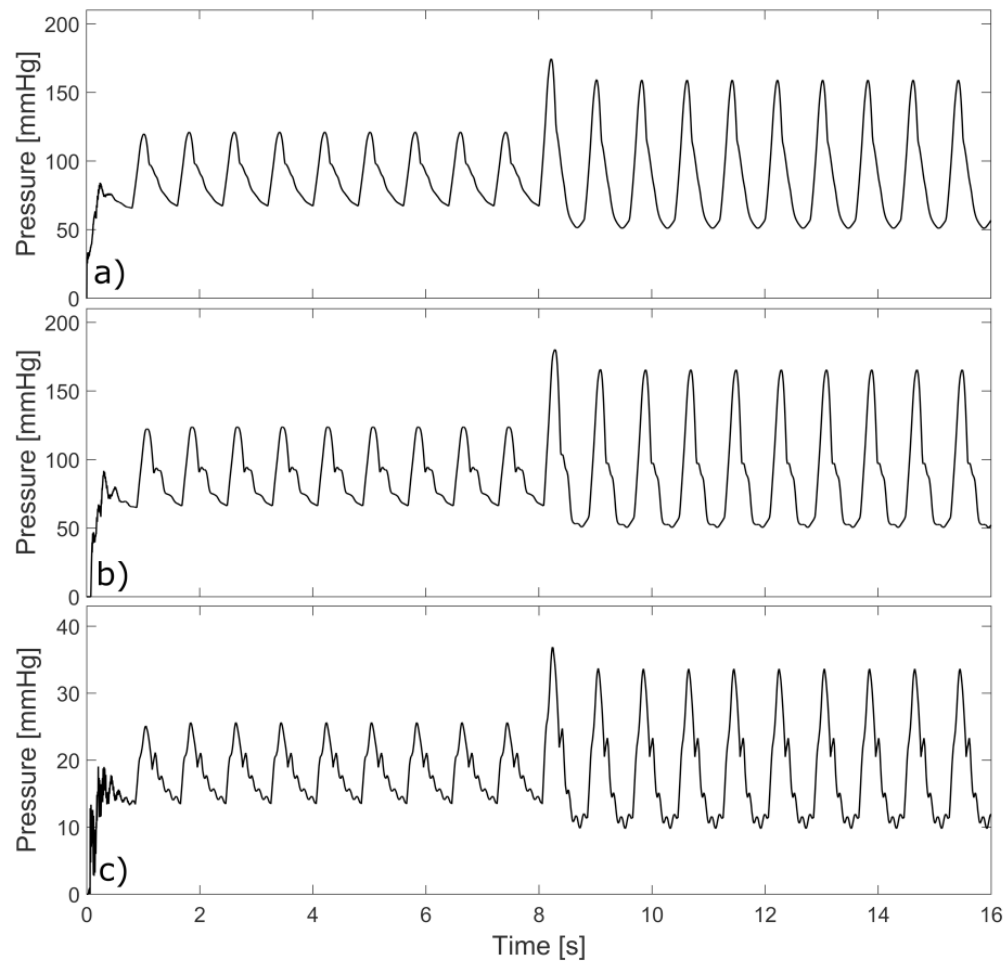

Fig. 5. The pressure waveform in a) ascending aorta, b) left brachial artery and in c) anterior communicating artery during 20 cycles of the heart at AR. The onset of AR takes place after 10 first cycles of heart

for further studies including the compensatory mechanisms that are intrinsically active and/ or of a feedback nature.

These models are the first attempts of studies of AS and AR with the use of a 1-D model of the arterial tree. The simulation data explain the physical consequences of AS and AR. The abrupt switching of the morbid reflection coefficients illustrates the earliest reaction of the pressure profiles on the AS and AR in the selected locations of the human systemic arterial system.

\section{Conclusions}

We have constructed a 1-D model of the arterial system that is able to reliably reproduce the most fundamental features of the propagation of the pulse waves [36, 37]. This kind of model is particularly effective in the description of large-scale properties of the entire arterial system and of its response to some lesions and/or external hazards. Here we have studied the reaction of the arterial system to perturbations caused by AS and AR. This phenomena were simulated in Avolio's model of 138 arteries with the Circle of Willis in it [10]. This new approach allowed us, for the first time, to determine the pressure waveforms during the AS and AR. 
To simulate the valvular heart diseases, the changes of the reflection coefficient of the aortic valve has been used. This simple approach allowed us to determine the earliest reactions of the arterial system to AS and AR.

During the AS we can see a significant decrease in the pressure waveform in the ascending aorta, in the left brachial artery and in the anterior communicating artery. Hoverer, the decrease is only in the systolic pressure. The diastolic pressure has not changed. In the case of AR we can see changes in amplitude of systolic and diastolic pressure. When, because of $\mathrm{AR}$, the systolic pressure increases at the same time the diastolic pressure decreases. These changes match the experimental observations of the phenomena.

The model can be used to predict the response of the human arterial system in many other physiological and pathological conditions.

\section{References}

[1] Chambers J.B., Aortic stenosis, European Journal of Echocardiography, Vol. 10, 2009, 11-19.

[2] Baumgartner H., Hung J., Bermejo J., Chambers J.B., Evangelista A., Griffin B.P., Iung B., Otto C.M., Pellikka P.A., Quinones M., Echocardiographic assessment of valve stenosis: Eae/ase recommendations for clinical practice, European Journal of Echocardiography, Vol. 10, 2009, 1-25.

[3] Bermejo J., The effects of hypertension on aortic valve stenosis, Heart, Vol. 91, 2005, 280-282.

[4] Schade R., Andersohn F., Suissa S., Haverkamp W., Garbe E., Dopamine agonists and the risk of cardiac-valve regurgitation, $\mathrm{N}$ Engl J Med, Vol. 356, 2007, 29-38.

[5] Zanettini R., Antonini A., Gatto G., Gentile R., Tesei S., Pezzoli G., Valvular heart disease and the use of dopamine agonists for parkinson's disease, N Engl J Med., Vol. 356, 2007, 39-46.

[6] Maurer G., Aortic regurgitation, Heart, Vol. 92, 2006, 994-1000.

[7] Pocock C., Chambers J., The patient with a systolic murmur: severe aortic stenosis may be missed during cardiovascular examination, QJM, Vol. 93, 2000, 685-688.

[8] Pasipoularides A., Clinical assessment of ventricular ejection dynamics with and without outflow obstruction, J Am Coll Cardiol, Vol. 15, 1990, 859-882.

[9] Wisenbaugh T., Spann J. F., Carabello B. A., Differences in myocardial performance and load between patients with similar amounts of chronic aortic versus chronic mitral regurgitation, J Am Coll Cardiol, Vol. 3, 1984, 916-923.

[10] Schwarz M., Nguyen M., Kiencke U., Heilmann C., Klemm R., Benk C., Beyersdorf F., Busch H., Integration of the circle of willis into avolio's model of the arterial haemodynamics, Proceedings of the Sixth IASTED International Conference Biomedical Engineering, 2008.

[11] Zamir M., Coverdale N., Barron C., Sawicki C., Shoemaker J., Baroreflex variability and "resetting": A new perspective, Journal of Biomechanics, Vol. 47, 2014, 237-244.

[12] Kember G., Armour J., Zamir M., Neural control hierarchy of the heart has not evolved to deal with myocardial ischemia, Physiological Genomics, Vol. 45, 2013, 638-644. 
[13] Ogoh S., Fadel P., Nissen P., Jans O., Selmer C., Secher N., Raven P., Baroreflex - mediated changes in cardiac output and vascular conductance in response to alterations in carotid sinus pressure during exercise in humans, J Physiol., Vol. 550, 2003, 317-324.

[14] Alastruey J., Parker K. H., Sherwin S. J., Arterial pulse wave haemodynamics, 11th International Conference on Pressure Surges, 2012, 401-443.

[15] Jagielska K., Trzupek D., Lepers M., Pelc A., Zieliński P., Effect of surrounding tissue on propagation of axisymmetric waves in arteries, Physical Review E, Vol. 76, 2007, 066304.

[16] Drochon A., Sinusoidal flow of blood in a cylindrical deformable vessel exposed to an external magnetic field, The European Physical Journal Applied Physics, Vol. 73, 2016, 18.

[17] Sherwin S.J., Peiro J., Parker K.H., One-dimensional modelling of a vascular network in space-time variables, J. Eng. Maths., Vol. 47, 2003, 217-250.

[18] Peiro J., Veneziani A., Reduced models of the cardiovascular system, Cardiovascular Mathematics, 2009, 347-394.

[19] Hughes T., Lubliner J., On the one-dimensional theory of blood flow in the larger vessels, Mathematical Biosciences, Vol. 18(1-2), 1973, 161-170.-

[20] Smith N.P., Pullan A.J., Hunter P.J., An anatomically based model of transient coronary blood flow in the heart, SIAM J. Appl. Math., Vol. 62, 2001, 990-1018.

[21] Hughes T.J.R., A study of the one-dimensional theory of arterial pulse propagation, $\mathrm{PhD}$ thesis, 1974.

[22] Vosse F.N. van de, Stergiopulos N., Pulse wave propagation in the arterial tree, Annu. Rev. Fluid Mech., Vol. 43, 2011, 467-499.

[23] Canic S., Kim E., Mathematical analysis of the quasilinear effects in a hyperbolic model of blood flow through compliant axi-symmetric vessels, Math. Meth. Appl. Sci., Vol. 26, 2003, 1161-1186.

[24] Quarteroni A., Formaggia L., Mathematical modelling and numerical simulation of the cardiovascular system, in Handbook of Numerical Analysis 12, Elsevier, 2004, 3-127.

[25] Womersley J.R., Method for the calculation of velocity, rate of flow and viscous drag in arteries when the pressure gradient is known. J Physiol. 127 (3), 1955, 553-563.

[26] Holzapfel G.A., Gasser T.C., Ogden R.W., A new constitutive framework for arterial wall mechanics and a comparative study of material models, J. Elasticity, Vol. 61, 2000, 1-48.

[27] Armentano R., Barra J., Levenson J., Simon A., Pichel R.H., Arterial wall mechanics in conscious dogs: Assessment of viscous, inertial and elastic moduli to characterize aortic wall behavior, Circulation Research, Vol. 76, 1995, 468-478.

[28] Armentano R., Megnien J.L., Simon A., Bellenfant F., Barra J., Levenson J., Effects of hypertension on viscoelasticity of carotid and femoral arteries in humans, Hypertension, Vol. 26, 1995, 48-54.

[29] Craiem D., Graf S., Pessana F., Grignola J., Bia D., Gines F., Armentano R., Cardiovascular engineering: modelization of ventricular arterial interaction in systemic and pulmonary circulation, Latin American Applied Research, Vol. 35, 2005, 111-114.

[30] Canic S., Tambaca J., Guidobon G., Mikelic A., Hartley C., Rosenstrauch D., Modeling viscoelastic behavior of arterial walls and their interaction with pulsatile blood flow, SIAM J. Appl. Math., Vol. 67, 2006, 164-193. 
[31] Saito M., Ikenaga Y., Matsukawa M., Watanabe Y., Asada T., Lagree P.-Y., Onedimensional model for propagation of a pressure wave in a model of the human arterial network: Comparison of theoretical and experimental results, J. Biomech. Eng., Vol. 133, $2011,121005$.

[32] Alastruey J., Khir A., Matthys K.S., Segers P., Sherwin S. J., Verdonck P., Parker K. H., Peiro J., Pulse wave propagation in a model human arterial network: Assessment of 1-d viscoelastic simulations against in vitro measurements, J. Biomech., Vol. 44, 2011, 2250-2258.

[33] Formaggia L., Lamponi D., Quarteroni A., One-dimensional models for blood flow in arteries, J. Eng. Math., Vol. 47, 2003, 251-276.

[34] Alastruey J., Parker K.H., Peiro J., Sherwin S.J., Lumped parameter outflow models for 1-d blood flow simulations: Effect on pulse waves and parameter estimation, Commun. Comput. Phys., Vol. 4, 2008, 317-336.

[35] Alastruey J., Parker K.H., Peiro J., Sherwin S.J., Analysing the pattern of pulse waves in arterial networks: a time-domain study, J. Eng. Math., Vol. 64, 2009, 331-351.

[36] Majka M., Gadda G., Taibi A., Gałązka M., Zieliński P., Protective properties of the arterial system against peripherally generated waves, Mathematical Biosciences, Vol. 286, 2017, 16-21.

[37] Majka M., Gadda G., Taibi A., Gałązka M., Zieliński P., The earliest effects of sudden occlusions on pressure profiles in selected locations of the human systemic arterial system, Physical Review E - in press, 2017. 